\title{
The Culture of Experience and the Culture of Noesis: Thoughts on the History and Future of CATTW/ACPRTS
}

\author{
Jennifer J. Connor \\ McMaster University
}

MY PERSPECTIVE ON THE DEVELOPMENT of the Canadian Association of Teachers of Technical Writing/Association canadienne des professeurs de rédaction technique et scientifique (CATTW/ACPRTS) likely diverges dramatically from others. Several reasons account for the somewhat philosophical approach I will take to exploring issues intrinsic to both the field of technical writing in Canada and its representation by CATTW/ACPRTS. First, the fact that I have not taught at all in the past five years has extracted me from the environment in which CATTW/ACPRTS members normally work; yet my removal from the routine maelstrom of classroom-based activity has allowed me to reflect on the field from a distance. Second, when I did teach, it was not in technical writing, but in communication courses within a social science rather than humanities or scientific framework. Third, my scholarly activities involve training and research in the history of communication, broadly construed to include the history of the printed book, authorship, publishers, distribution, libraries, reading and text. Over the past ten years most of my work, published and ongoing, focuses on medically- or health-oriented text in this communications circuit, text which may not involve "technical writing" as we know it.

Although this background shapes my perspective on CATTW/ACPRTS, it actually is in keeping with the society itself: members come from a variety of disciplines, both in training and in employment. A fundamental interest in the study of language, particularly language in use, has brought us together to share what we know from our disparate viewpoints. Despite this commonality of interest, however, CATTW/ACPRTS frequently manifests a certain schizophrenia at its conferences. Almost from its inception, calls have appeared for changes to its name from researchers who feel constrained by its narrow focus on "teachers" or from those who do not teach "technical" writing. Nevertheless, no substitute could be found that would cover all types of situations in which members find themselves. Although members now gener- 
ally feel comfortable with both the society's title and its scholarly direction, the most recent meeting in 1994 indicated that we have probably just submerged feelings of difference among members rather than dealing with them directly.

Since members' differences stem from the entirely distinct conceptual frameworks in which they operate, they are worthy of fuller thought than members can possibly give in the time allotted to general meetings. I'd therefore like to seize the opportunity of an historical celebration of CATTW/ACPRTS to explore the society's schizophrenic nature. After briefly re-considering the familiar "two culture" argument, I will suggest an alternative reading of members' belief systems as revealed through their own discourse.

\section{Are There Two Cultures in Teaching Technical Writing?}

The view of "two cultures" holds that people belong either to science or to arts: they supposedly think inductively, concentrating on details before seeing the whole picture, or deductively, immediately grasping the whole picture and filling in details as they go. Apart from the obvious problem of classifying those who can do both, this view stereotypes writers in both "cultures." If, as I believe, this is a myth of writer types, has it nonetheless influenced approaches taken to teaching technical writing? In subtle ways, perhaps it has. Demands for communication courses do not come from humanities or social science disciplines; they come from professional, technical or scientific programmes. Tacitly or otherwise, academe and the professions convey the idea that professional students alone need training in writing. And who teaches these courses? English graduates. Somehow the myth that English students intuitively know how to write-and can teach their knowledge to others-has maintained its hold on the provision of required writing courses at many institutions. This, despite the fact that English-speaking professional students often write concisely, clearly, and crisply in contrast to their peers in social science or the humanities who are wedded to diffuse, somnolent, and prolix prose. This too, despite the fact that even English instructors need help writing (as I and other editors can sadly attest).

How has the myth of the two cultures affected instructors of technical writing? If anything, it may have reinforced the distinction between "us" as purveyors of humanities wisdom and "them" as needing our unique insights to raise their literary (or social) consciousness. Treated with care, this attitude can, perhaps, be uplifting for students and instructors alike; handled 
imperiously, it can be a disaster for both disciplinary outlooks.

I suspect too that somehow intangibly this myth underlies tensions between practitioners or consultants who teach writing, college instructors who teach writing, and university professors who teach writing. Each group increases its humanities quotient and educational requirements for instructors, meaning greater adherence to humanities principles from one end of the spectrum to the other. Practitioners and consultants, not necessarily universityor humanities-trained, ground their teaching in their own immediate circumstance, drawing from actual incidents to inform their transfer of information in the classroom. Their work must be concrete and tied to the task at hand at a particular location-otherwise, they would not be able to justify their fee to the sponsoring business or agency. College instructors can also key their teaching to specific tasks owing to strong industry connections, although fewer may have as direct a writing practice as their consultant counterparts. University professors may have both direct writing practice and ties to industry, but their mandate is much larger: to train students to think critically, respond to situations creatively, and act flexibly in a variety of environments. As a result, their transfer of information must necessarily be more abstract and based more upon generalizable knowledge.

Added to the varying amount of humanities quotient in instructors, of course, are the varying levels of technical knowledge in their student populations. Consultants may teach graduated professionals-such as engineers, scientists, or health-care practitioners-all of whom have survived the deep socializing process associated with training in their profession. For these "students," too often, science and the arts have become irreconcilably separate. College instructors typically teach technicians whose philosophical outlook may already be entrenched in the "techie" versus "artsie" paradigm owing to educational streaming. And university professors from the humanities are parachuted into a tight professional curriculum in a manner that may devalue their worth for students aspiring to join the scientific perspective full-time.

In short, although these approaches to teaching writing can be complementary, and even cumulative in empowering students over time, they frequently may exacerbate underlying feelings of differential worth among instructors in each group. Ultimately, this may translate to tensions among members of each group who belong to CATTW/ACPRTS. 


\section{Other "Cultures" and Teaching Writing}

Deeper, underlying factors exist, I think, for the perceived differences among instructors of technical writing, factors which are more profoundly conceptual and which affect many, many fields of endeavour. Basically, these factors address what it is that we believe in, what it is that we believe we are doing, and what we feel is the best way to go about what we are doing. Others have analyzed the issues of belief systems and cultural, religious, or organizational structures far more eloquently, so rather than re-invent their discussions, I will present my interpretation of two cultures emerging in such organizations as CATTW/ACPRTS: the culture of experience and the culture of noesis. My views come from participant-observation over a ten-year period at CATTW/ACPRTS conferences and as a former editor of Technostyle; as well, they rely on analysis of the language and ethos employed by both of the two CATTW/ACPRTS cultures.

As an organization begins to form and create its own identity, enthusiasts come together to praise its merit and timeliness. CATTW/ACPRTS was no different. Early conferences provided welcome avenues for meeting others of a similar mindset and sharing personal experiences. Animated by their interaction, members took their renewed energy back to their institutions with added conviction of their own responsibility and self-worth-particularly as many held precarious appointments in their home institutions. In a religious model, these early conferences might be likened to evangelical camp meetings, where several days of total immersion in activities with like-minded people led to heightened awareness of matters personal and spiritual. Similarly, as with evangelical camp meetings, members of the assembled group emerged as activists. In promoting the cause, and carrying it forth to those unaware of it, they emphasized the value of experience. ${ }^{1}$

To garner support for their cause, they also adopted the ethos and language of those who seek converts. Their style thus favoured interactive, colloquial, conversational, inclusive and down-to-earth modes of address when speaking to audiences. By involving the audience directly in their own personal experience, they often presented two main types of ethos: the wounded healer and the enlightened prophet. In the first, speakers confessed their own weaknesses in teaching and writing before enjoining the audience to help by sharing their knowledge and their experience. In the second ethos, speakers provided an answer to a problem they themselves identified and showed the way for audience members to achieve equal success in teaching or writing of their own. At the same time, their presentations were marked by direct appeals 
to the audience (you) and frequent use of the first-person pronoun-all important features of the personal narrative which can still be seen in early issues of Technostyle. Over time, these appeals borrowed more overtly from conversion discourse: we are a "helping society," "if we all join in," we can "meet this challenge," our founder had an "innovative dream," "a vision," and it is "up to us to take that vision forward": "join me."

Early meetings, then, were marked by high emotional appeal and worked extremely well to gather people together and to promote their interests. Once converts have joined, however, other means are required to keep them interested and active, or they will tire of the predictability of personal conversion narratives. At the same time, as converts increasingly become part of the established order themselves - in the case of CATTW/ACPRTS, through tenure and promotion of the society's early, vulnerable members--there seemed less need to engage in conversion activities to prove self-worth. Instead, as with other organizations, CATTW/ACPRTS began to develop a structure tied to the established order, with its well-formed rules for conduct and, in effect, a liturgy based on norms of that order (humanities scholarship). Speakers drew not on personal experience, but on appeals to reason as illustrated in crafted arguments rather than emotive conversation. Their presentations reflected a different ethos - that of humble discoverer of general truths-as they adopted more measured, more tentative language. Action verbs became modals, otherwise emphatic statements qualified by "perhaps" as their focus shifts from person to thing examined: the evidence "indicates," "illustrates," "suggests" or "seems to suggest"; the study results "have implications" or offer "a step towards" understanding. These speakers conveyed their own deep belief that they could not hold out one way, but possible. ways, to tackle problems in teaching and writing. Their discourse reflects an emphasis on noesis, knowledge derived from intellect rather than experience.

In effect, CATTW/ACPRTS has developed along normal oranizational lines with normal organizational tensions between two competing conceptual frameworks. Those who excel at seeking converts and expanding the cause have actually moved beyond the field's normal boundaries, perhaps feeling their words are no longer reaching receptive audiences nearby. One longstanding CATTW/ACPRTS member, for example, recently wished to bring in new members and called on others to build a bigger base of membership. $\mathrm{He}$ spoke earnestly about taking the message overseas and to public schools: we should be involved; they need us, and don't know how to do it; we can go to all kinds of places where they're interested in knowing our subject; we should 
go out and help. His message no doubt frustrated those who do not share this vision of absorbing others' experience within one's own, but who seek instead to acknowledge and understand others' experiences on their own merit. Not surprisingly characterizing the former as imperialist activity, members in the noetic culture reject such "cultural colonialism," and call instead for "postcolonial" teaching. Their belief holds that instructors should draw attention to the implicit cultural hegemonies in which work-based writing take place, notably North American and managerial norms as opposed to other national or labour norms. These two conceptual frameworks of experience and noesis underpin CATTW/ACPRTS meetings so much that at least one experiencebased presenter recently felt she was "preaching to the converted."

\section{Accommodating Two "Cultures" in One Society}

Clearly these two cultures of experience and noesis continue to function in CATTW/ACPRTS. Rather than suppressing our awareness of them, we should celebrate their individual merits. CATTW/ACPRTS needs both cultures to maintain a healthy balance of establishment and newcomers. Not only should all members be encouraged to participate, including proselytizers, but members should investigate other possibilities that would address the needs of both cultures. Those emphasizing experience have frequently bemoaned the fact that CATTW/ACPRTS became intricately tied to the establishment order which favours noetic activity, even while they acknowledge that meeting with the Learned Societies, for example, has immeasurably helped build the prestige and respect accorded society members. Perhaps it is time to reconsider the context for CATTW/ACPRTS meetings to accommodate both member cultures.

CATTW/ACPRTS does not have to meet annually with the Learned Societies; contrary to common belief, funding for travel to meetings is not tied to the Learned Societies. In fact, unlike other learned societies, CATTW/ ACPRTS applies each year to the Social Science and Humanities Research Council under a separate, "Aid to Occasional Scholarly Conference" grant programme. (Other societies receive travel funds automatically either because they are full members of the Learned Societies-paying dues to the umbrella organization, the Canadian Federation of the Humanities-or because they receive three years of funding under SSHRC's "Aid and Attendance Grants to Scholarly Associations.") Not only can this separate grant be administered anywhere in Canada, but the fact that CATTW/ACPRTS is not a full-fledged member of the Learned Societies, combined with its small size, means it can 
be more flexible about meeting events.

The emphasis in any SSHRC grant application, understandably, will still be on demonstration of scholarly merit, regardless of meeting place. Another possibility for CATTW/ACPRTS might involve meeting with the Learned Societies in alternate years, to hold two different kinds of conferences. That way, all members benefit by knowing where they fit in and what to expect-to say nothing of expanding the number of people for presentations which have too frequently devolved upon the same authors for years. Perhaps professional societies in Canada would be interested in co-sponsoring CATTW/ACPRTS meetings, or encouraging a CATTW/ACPRTS meeting held in conjunction with their own. This approach has been successfully followed by the Bibliographical Society of Canada, for example, which routinely alternates its conference each year to meet with the Learned Societies and the Canadian Library Association; scholars and practitioners both profit from this arrangement. Similarly, other Canadian societies have opted in and out of the Learneds to meet their particular needs, such as the Folklore Studies Association of Canada, which met separately in the Maritimes rather than the West Coast one year because most of its members work in Central and Eastern Canada. Why not consider varying the venue for meetings of CATTW/ACPRTS as well? This is merely one suggestion for meeting the needs of two distinct cultures both creatively and proactively. Frank discussion should generate a range of exciting possibilities for CATTW/ACPRTS to maintain its momentum over the next ten years.

Ideas expressed here are deeply indebted to William Westfall's Two Worlds: The Protestant Culture of Nineteenth-Century Ontario (Montreal and Kingston: McGill-Queens University Press, 1989). While informing my understanding of organizational patterns in protestant religion and their concomitant discourse strategies, however, Westfall's work does not accord in all respects with my representation here.

They are also influenced, of course, in subtler ways by writers such as Walter J. Ong, especially his Orality and Literacy: The Technologizing of the Word (London and New York: Routledge, 1982). 
